\title{
Inhaled disodium cromoglycate (DSCG) as maintenance therapy in children with asthma: a systematic review
}

\author{
M J A Tasche, J H J M Uijen, R M D Bernsen, J C de Jongste, J C van der Wouden
}

\begin{abstract}
Background-Disodium cromoglycate (DSCG) is included in the BTS guidelines on the treatment of asthma for use in children, but is now used only infrequently. We have identified and interpreted the findings of all published randomised, placebo controlled trials of DSCG in the prophylactic treatment of children with asthma.
\end{abstract}

Methods-Several databases were searched to identify trials. Studies were included if they investigated subjects with asthma aged 0-18 years old, addressed maintenance treatment with inhaled DSCG, and were published in English. The methodological quality of the studies was assessed independently by three reviewers. The $95 \%$ confidence intervals (CI) of differences in the treatment effect for cough and wheeze between placebo and treatment with DSCG were computed. The estimates were pooled and tested for homogeneity and, to assess possible publication bias, a funnel plot was made and tested for symmetry.

Results-Of the 24 randomised, placebo controlled trials identified, the methodological scores varied widely. The null hypothesis of homogeneity was rejected. Under the assumption of heterogeneity the overall $\mathrm{CI}$ for wheeze was 0.11 to 0.26 and for cough was 0.13 to 0.27 . The overall tolerance intervals $(-0.11$ to 0.48 and -0.04 to 0.43 for wheeze and cough, respectively) both included zero, so it cannot be concluded that future studies will show an effect of DSCG compared with placebo. Older studies were more often in favour of DSCG. The funnel plots suggest publication bias; small studies with negative or equal outcomes are lacking.

Conclusion-Given the apparent publication bias, the small overall treatment effect, and the tolerance interval including zero, there is insufficient evidence that DSCG has a beneficial effect as maintenance treatment in children with asthma. (Thorax 2000;55:913-920)

Keywords: disodium cromoglycate; asthma; children

Dr J C van der Wouden

vanderwouden@hag.fgg.eur.nl

Received 31 January 2000

Returned to authors

18 April 2000

Revised manuscript received

30 June 2000

Accepted for publication

17 July 2000

Several guidelines for the management of childhood asthma have been published by international consensus groups, recommending early preventive treatment to reduce the need for bronchodilators and to enable asth- matic children to lead a normal and active life. ${ }^{12}$ The consensus statements recommend disodium cromoglycate (DSCG) as maintenance treatment for children with moderate asthma. DSCG is supposed to be effective in $60 \%$ of cases, ${ }^{3}$ but predictors of success are not known. Although it has been used for decades, the precise mechanism of its action is still not fully understood. No serious side effects have been reported in trials, but occasional cases of dysuria, urticaria, bronchospasm, angiooedema, and anaphylaxis have been reported. ${ }^{4-6}$

In the current review and position statement of the British Thoracic Society published in 1997 DSCG and inhaled corticosteroids were both recommended as first choice preventive treatment in young children rather than DSCG being recommended as the first choice before inhaled corticosteroids ${ }^{7}$; the grounds for this decision are, however, still unclear. The long term side effects of prophylactic treatment with inhaled steroids in early childhood are unknown. Nevertheless, there is concern that treatment of very mild cases of asthma with inhaled steroids may have an adverse effect on the balance between risk and benefit, so DSCG may still be considered as first choice preventive treatment. ${ }^{7}$ Other guidelines continue to recommend DSCG as first choice in young children. $^{8}$

The use of DSCG has decreased since 1990 while the use of inhaled corticosteroids is increasing, even in young children. ${ }^{9}{ }^{10}$ Nowadays, few consultant paediatricians use DSCG as first line treatment in young children ${ }^{11}$ while some studies suggest overtreatment of children with mild asthma with inhaled corticosteroids. $^{9}{ }^{12}$

Because of the discrepancy between guidelines and daily practice and the debate on the role of DSCG which led to its withdrawal as first line treatment in young children, we have undertaken a systematic review of all published randomised, placebo controlled trials of DSCG in the prophylactic treatment of asthma in children. The aim of the study was to assess the methodological quality of the studies and the effectiveness of inhaled DSCG by statistical pooling of the study results.

\section{Methods}

DATA SOURCES AND STUDY SELECTION

Literature searches of Medline, Embase, the Cochrane Controlled Trial Register, ${ }^{13}$ and the database of the manufacturers of DSCG were carried out for the period from January 1966 to 


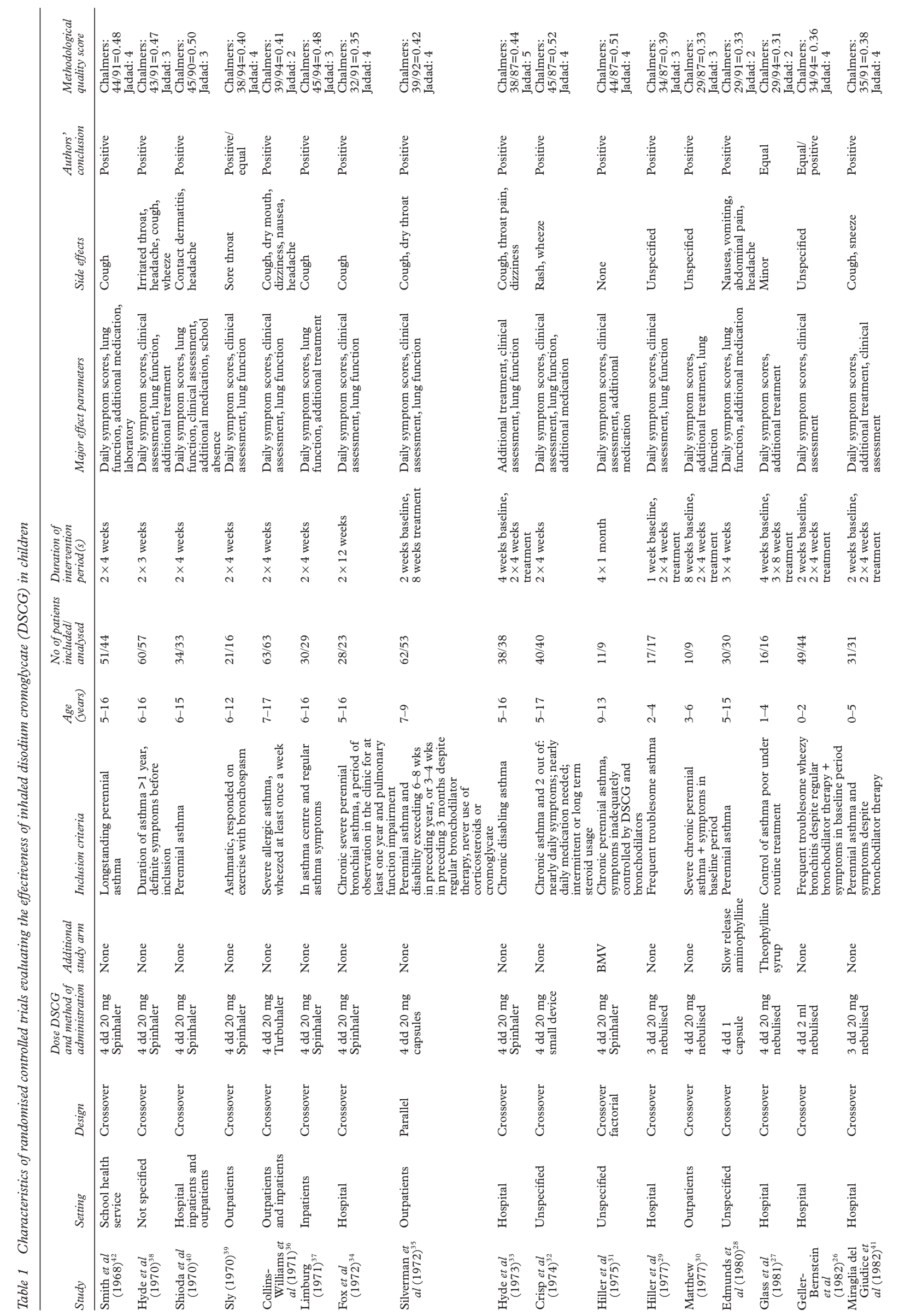




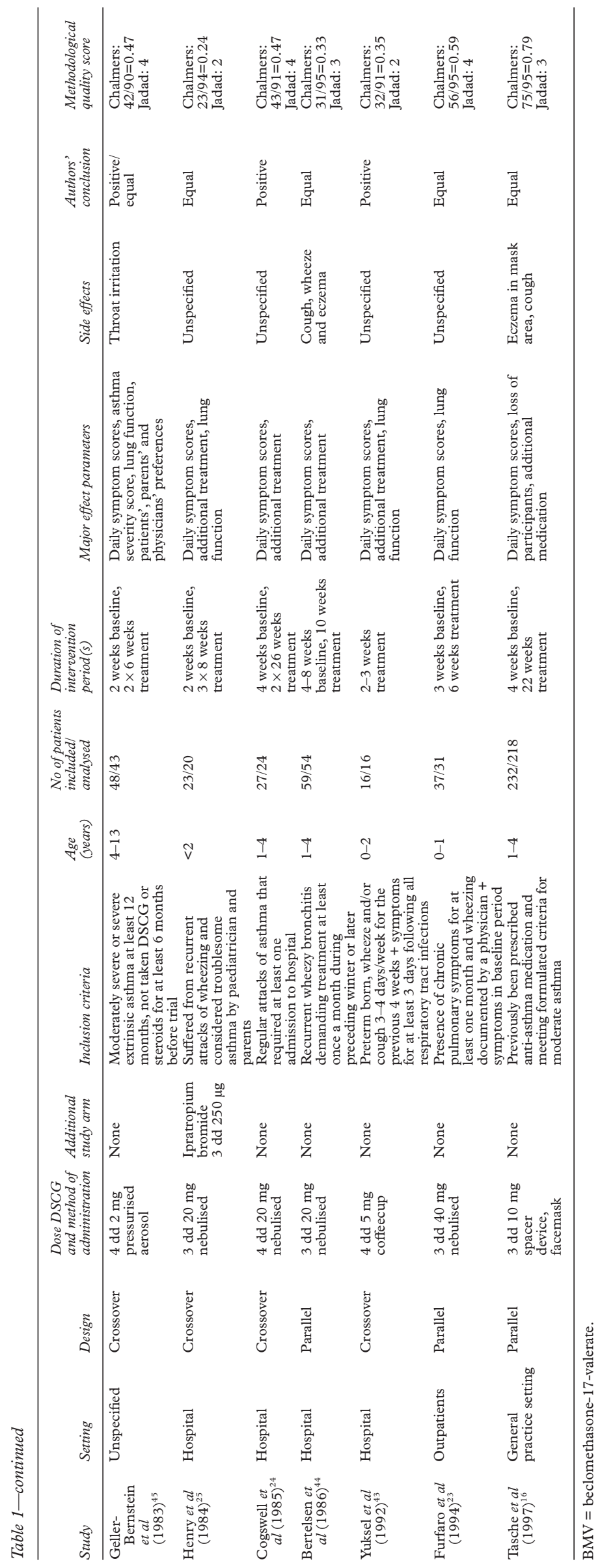

January 1999. The MESH keywords "asthma", "sodium cromoglycate", and "clinical trial" were used to identify relevant articles. After the search we reviewed the reference lists of all relevant articles and selected all double blind, placebo controlled, randomised clinical trials of maintenance treatment of children aged 0-18 years published in English.

\section{DATA EXTRACTION}

Methodological assessment

All trials were scored according to the criteria of Chalmers ${ }^{14}$ and Jadad ${ }^{15}$ independently by two of three reviewers (MJAT, JHJMU, JCvdW), two general practitioners, and a methodologist. Before scoring the trials the reviewers mutually adjusted their interpretation of the items. The results were discussed in a consensus meeting; in cases where there was a lack of consensus the assessment of the third reviewer determined the final decision. To avoid "reviewers' review bias" our own trial $^{16}$ was also scored by an impartial reviewer (S M A Bierma-Zeinstra).

\section{Description of the studies}

The methods and conclusions of the different trials were summarised and tabulated and the general outcome of each study was derived from the conclusions drawn by the authors. A study was judged positive when the authors concluded that DSCG was more effective than placebo and equal when the authors reported no difference between the treatments.

\section{Statistical pooling}

For each study the $95 \%$ confidence interval (CI) for the difference in symptom scores between placebo and DSCG treatment was calculated separately for wheeze and cough. If no separate scores were available we used the score given for daily symptoms. If the published data were not sufficient to compute a 95\% CI and the trial was published not more than five years ago, we requested the data from the authors. If, apart from the statement "not significant", no exact $p$ value was given, we calculated the effect of two extreme alternatives $(\mathrm{p}=0.10$ and $\mathrm{p}=0.90)$. Most studies used a scale of $0-3$; when a different scale was used it was transformed for our purposes.

\section{DATA SYNTHESIS}

We computed the pooled estimates of the treatment effect and the pooled $95 \% \mathrm{CI}$ and tested the hypothesis of homogeneity. ${ }^{17}$ In case of heterogeneity the pooled CI was computed taking heterogeneity into account. ${ }^{17}$ We also computed the corresponding tolerance interva $l^{18}$ to determine the range of outcomes of the studies. In order to explain heterogeneity the influence of study characteristics on the outcome was evaluated by means of univariate and multivariate regression analysis (observations weighted by the reciprocal of the square of the standard error of the mean difference between placebo and DSCG). The influence of asthma severity of the study population (expressed in the mean placebo score) on the outcome was evaluated by means of functional 

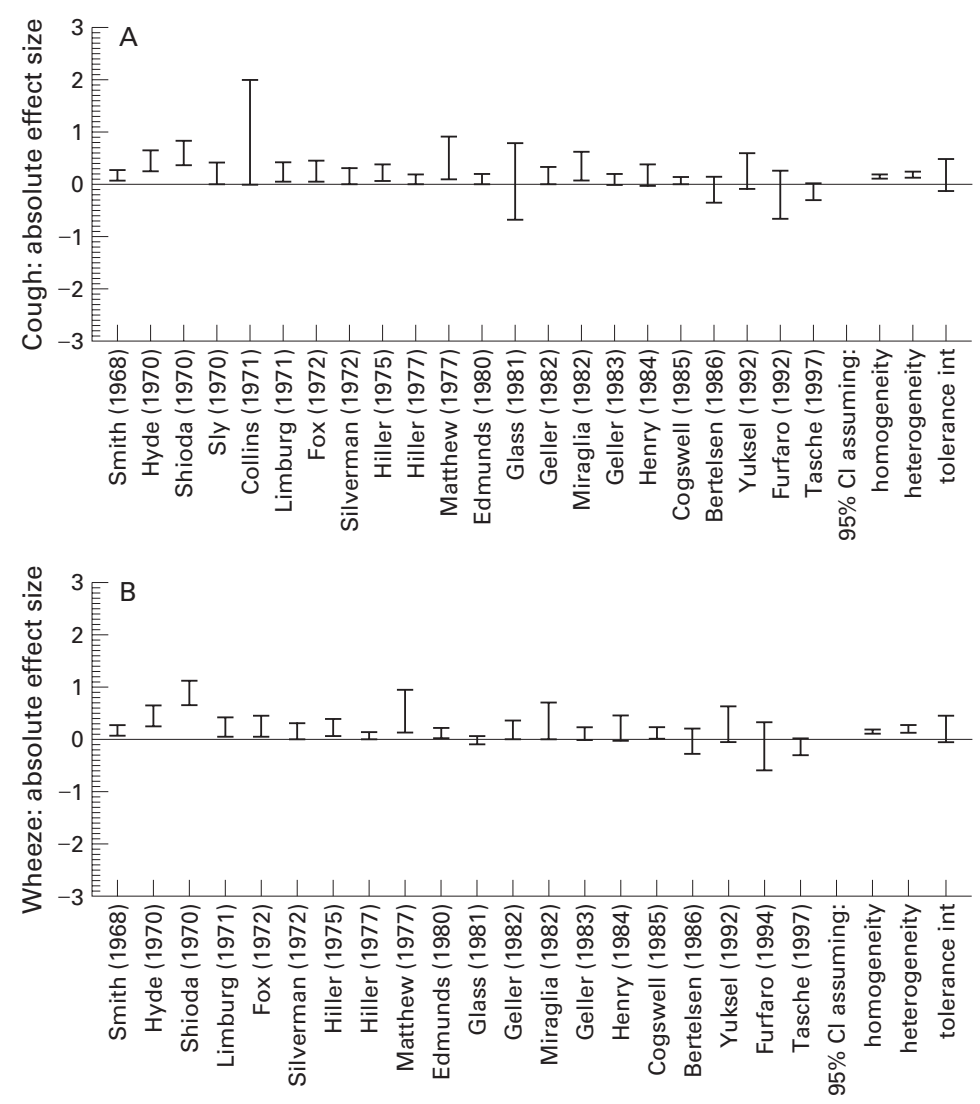

Figure 1 95\% confidence intervals of absolute difference for $(A)$ cough and $(B)$ wheeze in DSCG group compared with placebo.
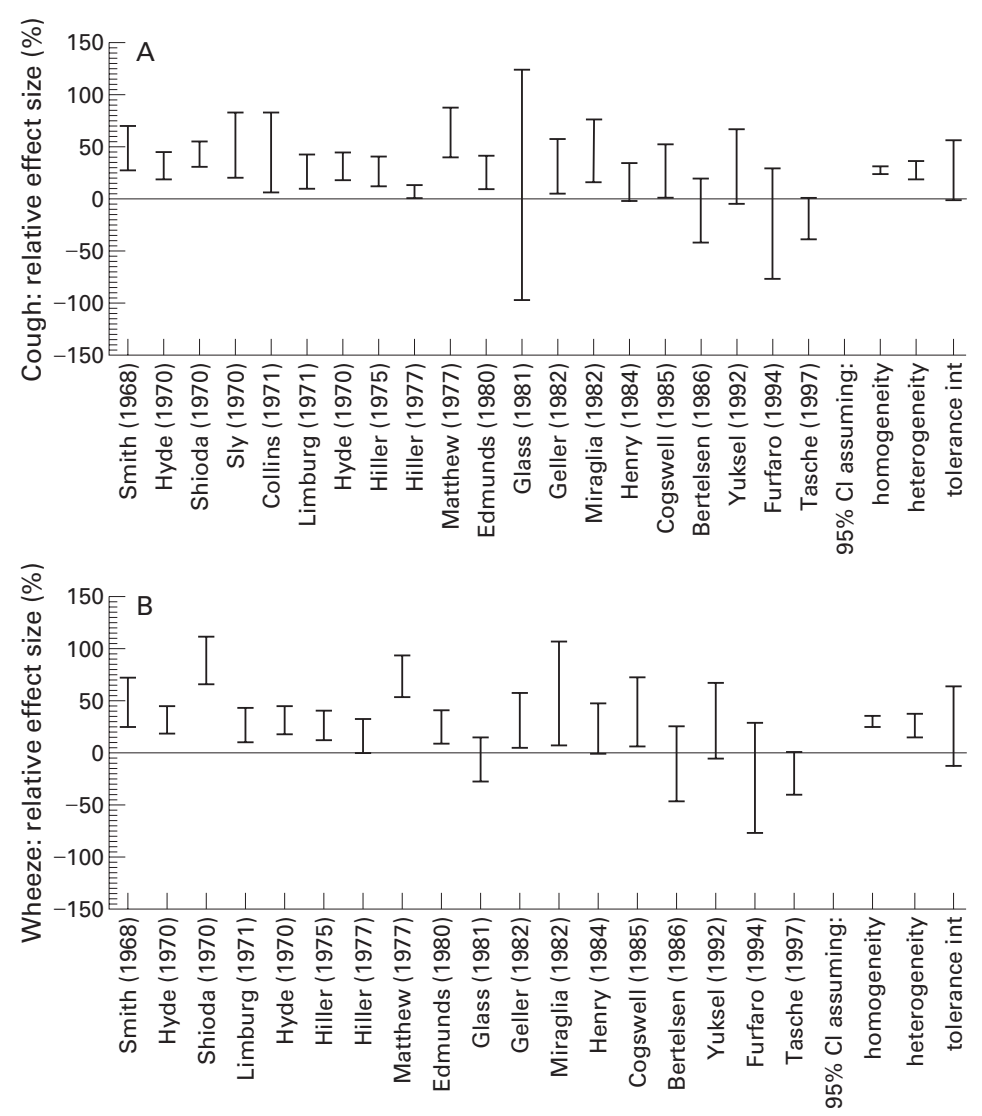

Figure 2 95\% confidence intervals of \% improvement for (A) cough and (B) wheeze in DSCG group compared with placebo. relationships. ${ }^{19}$ To explore heterogeneity and publication bias further a funnel plot was constructed of the effect estimate (for wheeze and cough) against the precision ${ }^{20}$ for all trials. The precision of a trial was defined as $1 /$ standard error. When no exact $\mathrm{p}$ value was given (see above) a $p$ value of 0.10 was assumed. The symmetry of the funnel plot was tested using a threshold $\mathrm{p}$ value of $0.10 .^{21}$

To show the relative difference in treatment effect the relative improvement in mean (RIM $=$ percentage improvement compared with placebo) was calculated for each study, as proposed by Calpin et $a l^{2}$ :

RIM = (mean score (placebo) -mean score $(\mathrm{DSCG})) \times 100 /$ mean score (placebo)

Similar pooling and testing for homogeneity as described above was performed; for this procedure a first order approximation was used as an estimate of the standard error of the RIM.

\section{Results}

STUDIES

A total of 251 articles was identified in Medline of which 18 met our inclusion criteria. ${ }^{23-40}$ Embase provided one additional trial, ${ }^{16}$ and two additional trials were provided by the database of the pharmaceutical company. ${ }^{4142}$ The Cochrane Controlled Trial Register did not supply further trials but two more trials were found by searching the references of relevant articles. ${ }^{43}{ }^{44}$ One additional trial ${ }^{45}$ was revealed to us by an expert in the field who also pointed out the trial by Shioda ${ }^{40}$ which we had overlooked in the Medline search. Excluded studies were either not double blind, not randomised, not controlled, did not concern the appropriate age group, or investigated the effectiveness of DSCG in exercise induced asthma; one double blind crossover study was excluded because the results were only partially presented. ${ }^{46}$ Thus, 24 randomised controlled trials of DSCG as a prophylactic agent in children with asthma were reviewed (table 1). Most of the studies were European $(n=14,10$ of which were British) or North American $(n=7)$. Two studies were performed in Israel and one in Japan. Studies differed in design, severity of asthma, number of children included, age of children, administration of medication, and follow up period. In total, more than 1000 children were studied in the 24 trials with sample sizes ranging from nine to 218; about half of the children (11 trials) were of preschool age and half were five years or older (13 trials). Before 1977 the studies included only children aged four years and over. The median duration of intervention (period of active medication in case of crossover studies) was 4 weeks (range 3-26). All studies included children with moderate to severe asthma, and all but one study were hospital based. In nine papers it was unclear whether the population was hospitalised or ambulatory, nor was it clear whether and what concurrent medication was permitted during the trial. ${ }^{24} 2631343638394145$ Only one trial selected children with moderate asthma through general practitioners. ${ }^{16}$ Compliance was discussed in only five papers. ${ }^{1623272842}$ 
SIDE EFFECTS

Fifteen of the trials reported side effects, all of which were minor with a low incidence. Cough was most often reported, followed by bitter taste, wheezing, sneezing, throat irritation, and perioral eczema. Some studies did not specify the kind of adverse effects but merely stated "minor".

OUTCOME

A positive outcome was concluded by the authors in 16 of the studies and in three the outcome was partially positive, depending on age $^{26}$ and outcome measure. ${ }^{39} 45$ Five of the trials had an equal outcome. No studies in favour of placebo treatment were found.

\section{METHODOLOGICAL ASSESSMENT}

The results of the methodological assessments are given in the last column of table 1.The Chalmers scores ranged from $24 \%$ to $79 \%$ with a mean score of $43 \%$ indicating mediocre methodology. The most prevalent methodological shortcomings were in the areas of compliance, selection and inclusion, and statistics and analysis. The descriptions of blinding and intervention were relatively good. Fourteen studies were published before 1980 and the mean method score for these was similar to
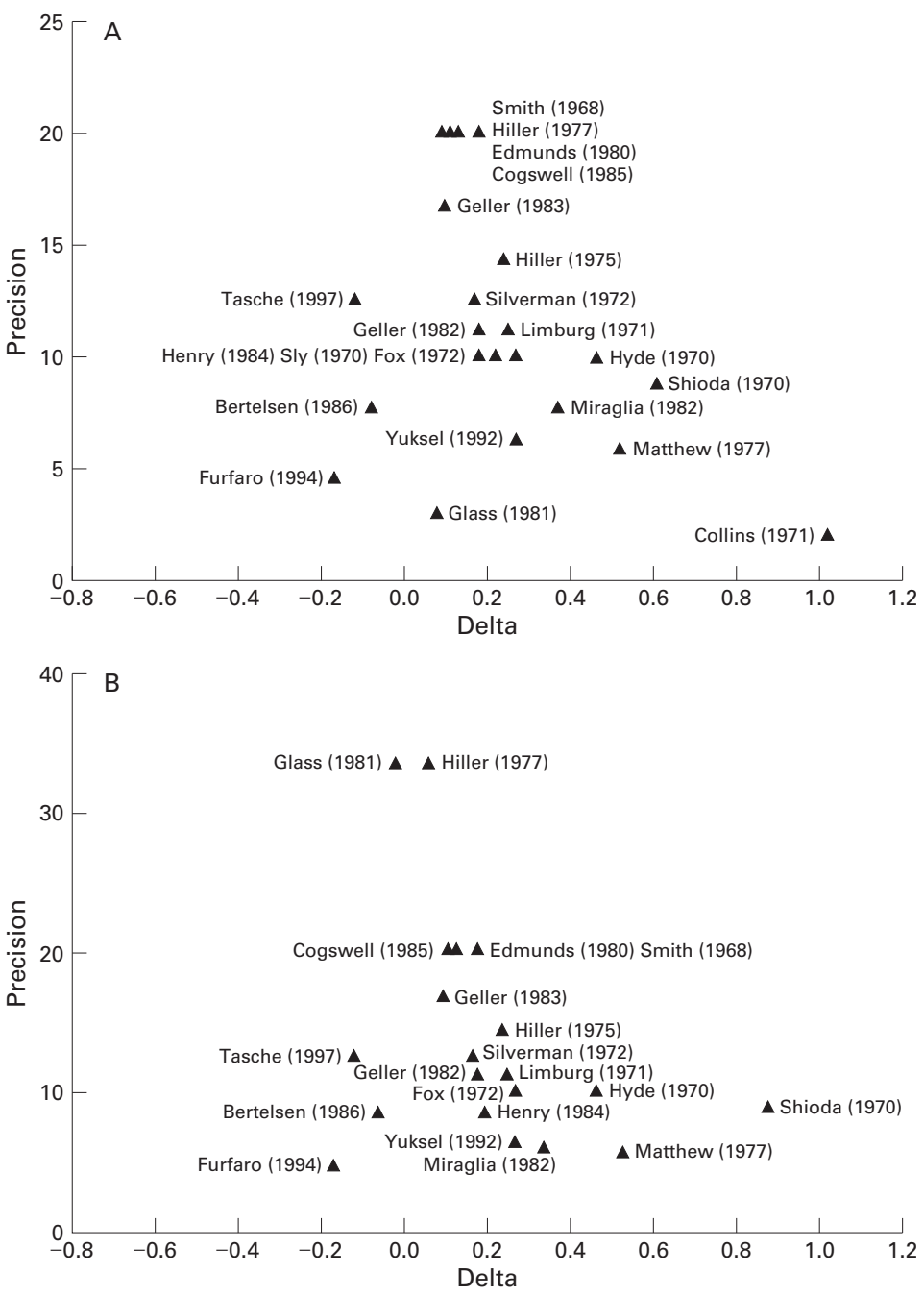

Figure 3 Funnel plots for (A) cough (22 studies) and (B) wheeze (20 studies). that for the 10 trials reported after 1980. Our own recent study scored highest; to control for reviewers' review bias the independent observer re-evaluated our study which resulted in similar scores. The Jadad scores ranged from 2 (five studies) to the maximum of 5 (one study).

STATISTICAL POOLING

For most studies the data were insufficient to allow a formal meta-analysis with odds ratios. Two studies did not give symptom score data or data that could be converted into symptom scores. ${ }^{32}{ }^{33}$ Figure 1 presents two graphs of $95 \%$ CIs of differences in mean symptom score (placebo minus DSCG) for each study. The CIs are ordered according to year of publication of the study. In eight studies the CIs were calculated using the separate symptom score of wheeze and cough, and in 12 studies we used daytime symptoms. In two studies ${ }^{36} 39$ only the results for cough were presented; data on wheeze were not published because the difference in treatment effect between placebo and DSCG was not significant.

The $\chi^{2}$ test rejected the hypothesis of homogeneity of the study results $(\mathrm{p}<0.001)$, both for the absolute and the relative outcome measures. Taking heterogeneity into account, the pooled $95 \%$ CIs for wheeze and cough were 0.11 to 0.26 and 0.13 to 0.27 , respectively, and the pooled $95 \%$ CIs for RIM were 0.16 to 0.37 and 0.19 to 0.36 . The heterogeneity was not related to the placebo symptom level (that is, severity of asthma), method of administration of the medication, duration of follow up, frequency of dosage, methodological scores, and other study characteristics. Only year of publication, age of the children, study design, and duration of follow up were significant predictors of outcome in the univariate regression analysis. The multivariate regression analysis showed that only year of publication was a significant predictor of effect size: older studies were more likely to produce a positive effect of DSCG treatment. Age of the children, which was strongly correlated with year of publication $(\rho=0.82)$, was not significant in this analysis. The pooled $95 \%$ CIs under the assumption of heterogeneity and the corresponding tolerance intervals are shown in figs 1 and 2. The latter include zero, both for the absolute treatment effect $(-0.11$ to 0.48 for wheeze, -0.04 to 0.43 for cough) and for the relative treatment effect $(-0.12$ to 0.64 for wheeze, -0.02 to 0.57 for cough). The funnel plots are shown in fig 3; the hypothesis of symmetry was rejected for both cough $(p=0.095)$ and wheeze $(p=0.01)$. The asymmetrical funnel plots show that studies with low precision and negative outcome are underrepresented, indicating publication bias.

\section{Discussion}

Our results show heterogeneity of study results, a small overall treatment effect, and publication bias indicated by the absence of small negative trials.

\section{STUDY CHARACTERISTICS}

Although DSCG was indicated as treatment for mild to moderate asthma, nearly all trials 
comprised hospital based populations of children with moderate to severe asthma. Nine studies administered the medication with a nebuliser. Nowadays, spacer devices are available for young children which are less time consuming and less tedious to use than nebulisers, particularly at home. Metered dose inhalers with spacer devices were used in only two studies. ${ }^{16} 43$ Spinhalers were used in 11 trials with older children. The method of administration, a critical factor in delivery of drugs to the lungs, was not a predictor of outcome.

The diagnosis and measurement of asthma in young children is difficult ${ }^{47}{ }^{48}$ and age effects might reduce or mask the effects of DSCG. However, this is unlikely since, although children's age was a significant predictor for treatment effect in the univariate analysis, the multivariate analysis showed that publication date of the trial was a confounder for age of the children. Duration of follow up in most of the trials did not exceed four weeks which may be too short to assess the effect of the treatment. Although the duration of follow up was not a predictor of outcome, it was notable that none of these short term trials had an "equal" conclusion (12 were positive and two were positive/equal). In seven studies the authors tried to find characteristics or criteria to predict which children would respond to DSCG but none were found. ${ }^{16242534353744}$ Silverman et al ${ }^{35}$ reported that only the acute protective effect of DSCG in exercise tests predicted the probable success or failure of long term treatment with the drug.

EARLIER REVIEWS

The effects of treatment with DSCG have been reviewed previously. Edwards ${ }^{49}$ examined the evidence for the anti-inflammatory action of DSCG in adults and children in a large number of controlled and uncontrolled studies but it is unclear how these were selected. Hoag and

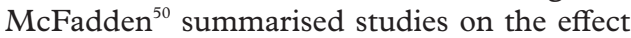
of DSCG on bronchial hyperreactivity in adults and children. The review by Schweitzer and Brossier Ballano ${ }^{51}$ discussed three controlled studies assessing the efficacy of DSCG in children aged two years and younger. Finally, Holgate $^{52}$ reviewed recent trials with metered dose inhalers in children and adults and discussed challenge studies, therapeutic studies, and the long term effects of DSCG. None of these earlier reviews were systematic, assessed the methodological quality, or tried to quantify treatment effects.

\section{METHODOLOGICAL ASSESSMENT}

Meta-analyses have been criticised but they are becoming increasingly popular because they give insight into the combined results of trials and provide data for rational decision making. ${ }^{53}{ }^{54}$ A review of scales and checklists for assessing the quality of randomised controlled trials shows limitations in virtually every scale. ${ }^{55}$ We decided to use the items proposed by Chalmers ${ }^{15}$ because these address both the methodology and the presentation of the study extensively. However, we found shortcomings while using the scale, including the lack of attention to sample size, protocol violations, and permitted concurrent medication. The methodological quality of the trials was mediocre, as shown by the mean score of $43 \%$ of the maximum attainable. We have to take into account the fact that 13 studies were published before 1980. Informed consent, clear description of inclusion criteria, rejection logs and baseline characteristics, adequate sample size calculation, calculation of confidence intervals, and regression analysis were not common practice at that time.

We also scored the trials according to the criteria of Jadad as this is the only validated scoring system available. ${ }^{15}$ This scoring system was not found to be very discriminatory because, when dealing with randomised, placebo controlled trials only, as in our review, the outcome score was limited to 2-5. However, half of the studies scored 3 points or less, which is compatible with serious or extensive flaws.

STATISTICAL POOLING

The estimates of the differences between placebo and DSCG treatment for cough and wheeze symptom scores (assuming heterogeneity) were 0.17 and 0.11 , respectively, which suggests a small therapeutic effect for DSCG. We doubt whether an effect of this size is of clinical relevance. On the other hand, the overall relative improvement estimates were $27 \%$ and $26 \%$, respectively. This considerable relative improvement combined with the minor absolute improvement shows that, overall, the severity of symptoms under placebo treatment was low. Indeed, although most studies in our review included children with severe asthma, the mean daily symptom score in the placebo groups was low (0.8), probably because of dilution by symptom free days which is a common finding in trials of childhood asthma. ${ }^{56} 57$

Care must be taken in drawing definitive conclusions about the role of DSCG in the treatment of asthma in children on the basis of this review for several reasons. Medical literature can be misleading as a result of selective submission and publication of randomised controlled trials showing a statistically significant treatment effect. ${ }^{58}$ The year of publication of the study proved to be the most significant predictor of treatment effect and the asymmetrical shape of the funnel plots suggests bias; studies with a positive treatment effect had relatively little precision and most were performed before 1980. Trials with little precision and a negative outcome have probably not been submitted or published, which is understandable in a period when a newly developed drug is tested and marketed. Our meta-analysis is therefore optimistic in its outcome; the addition of unpublished negative trials would change the results towards an even more negative conclusion.

The trials were heterogeneous in their treatment effects. Refraining from pooling was seriously considered, given the heterogeneity and the suspected publication bias. Nevertheless, we calculated the pooled confidence intervals and the tolerance intervals because these are 
useful summary measures. In cases of heterogeneity, in particular, we consider the tolerance interval to be more informative than the (heterogeneous) confidence interval because the first gives the range of treatment effects found by studies while the latter is a confidence interval for a theoretical treatment effect.

In two trials ${ }^{36}{ }^{39}$ the results for wheeze were not published because the difference between placebo and DSCG was not significant. This could result in some bias in favour of DSCG in the calculation for wheeze. On the other hand, two trials $^{32} 33$ with a positive outcome were omitted from the pooling because the published data were insufficient. The results of the statistical pooling were based on symptoms only because symptom scores were available in all trials.

We did not include studies on the immediate effects of DSCG on exercise induced asthma. This is a different issue which does not pertain to the use of DSCG as advised in the current guidelines. Finally, we did not include studies on the effects of combined treatment-that is, the corticosteroid sparing effects of DSCG.

Given the strong indication of publication bias, the tolerance interval including zero, and the small overall treatment effect, we conclude that, on the basis of published randomised trials, the superiority of DSCG over placebo in the maintenance treatment of children with asthma is not proven. We therefore consider that it is no longer justified to recommend DSCG as a first line prophylactic agent in childhood asthma.

We thank Fisons plc, Loughborough, UK for searching their database for clinical trials, Dr A Edwards for pointing out two trial reports, and S M A Bierma-Zeinstra for scoring our trial.

1 British Thoracic Society and others. Guidelines for the management of asthma: a summary. BMF 1993;306:138690 .

2 Warner JO, Neijens HJ, Landau LI, et al. Asthma: a follow Warner JO, Neijens HJ, Landau LI, et al. Asthma: a follow
up statement from an international paediatric asthma conup statement from an international paediatric

3 Warner JO. The place of Intal in paediatric practice. Respir Med 1989;83(Suppl):33-7.

4 Scheffer A, Rocklin R, Goetzl E. Immunologic components of hypersensitivity reactions to cromolyn sodium. $N$ Engl $f$ Med 1975;293:1220-4.

5 Ahmad S. Cromolyn sodium and anaphylaxis. Ann Intern Med 1983;99:882.

6 Lester MR, Bratton DL. Adverse reactions to cromolyn sodium: patient report and review of the literature. Clin Pediatr 1997;36:707-10.

7 British Thoracic Society, National Asthma Campaign, Royal College of Physicians of London, et al. British guidelines on asthma management: 1995 review and position statement. Thorax 1997;52(Suppl):S1-21. 8 Sly RM. New guidelines for diagnosis and management of

9 Warner JO. Review of prescribed treatment for children with Warner JO. Review of prescribed treatment

10 Price JF, Weller PH. Comparison of fluticasone propionate Price JF, Weller PH. Comparison of fluticasone propionate
and sodium cromoglycate for the treatment of childhood and sodium cromoglycate for the trea
asthma. Respir Med 1995;89:363-8.

11 Robins AW, Lloyd BW. Most consultants deviate from asthma guidelines. $B M \mathcal{F}$ 1995;311:508.

12 Paterson NAM, Peat JK, Mellis CM, et al. Accuracy of asthma treatment in schoolchildren in NSW, Australia. Eu Respir f 1997;10:658-64.

13 Cochrane Collaboration. The Cochrane Controlled Trial Register. Update 1990/1. Oxford: Update Software, 1999

14 Chalmers TC, Smith H, Blackburn B, et al. A method for assessing the quality of a randomized control trial. Controlled Clin Trials 1981;2:31-49.

15 Jadad AR, Moor A, Carroll D, et al. Assessing the quality of reports of randomised clinical trials: is blinding necessary? Controlled Clin Trials 1996;17:1-12.

16 Tasche MJA, van der Wouden JC, Uijen JHJM, et al. Randomised placebo-controlled trial of inhaled sodium cromoglycate in 1-4 year old children with moderate cromoglycate in $1-4$ year old chill
asthma. Lancet 1997;350:1060-4.
17 Dersimonian R, Laird N. Meta-analysis in clinical trials. Controlled Clin Trials 1986; 7:177-88.

18 van Houwelingen HC. Meta-analysis; methods, limitations and applications. Biocybernetics Biomed Engineering 1995; 15:53-61.

19 Bernsen RMD, Tasche MJA, Nagelkerke NJD. Variation in baseline risk as an explanation of heterogeneity in meta-analysis. Stat Med 1999;18:233-8.

20 Egger M, Davey Smith G. Misleading meta-analysis. BMF 1995;310:752-4.

21 Egger M, Davey Smith G, Schneider M, et al. Bias in metaanalysis detected by a simple, graphical test. $B M \mathcal{F}$ 1997;315:629-34

22 Calpin C, Macarthur C, Stephens D, et al. Effectiveness of prophylactic inhaled steroids in childhood asthma: a systematic review of the literature. $\mathcal{f}$ Allergy Clin Immunol 1997;100:452-7.

23 Furfaro S, Spier S, Drblik SP, et al. Efficacy of cromoglycate in persistently wheezing infants. Arch Dis Child 1994;71: $331-4$.

24 Cogswell JJ, Simpkiss MJ. Nebulised sodium cromoglycate in recurrently wheezy preschool children. Arch Dis Child 1985;60:736-8

25 Henry RL, Hiller EJ, Milner AD, et al. Nebulised pratropium bromide and sodium cromoglycate in the first two years of life. Arch Dis Child 1984;59:54-7.

26 Geller-Bernstein C, Levin S. Nebulised sodium cromoglycate in the treatment of wheezy bronchitis in infants and young children. Respiration 1982;43:294-8.

27 Glass J, Archer LNJ, Adams W. Nebulised cromoglycate, theophylline, and placebo in preschool asthmatic children. Arch Dis Child 1981;56:648-51.

28 Edmunds AT, Carswell F, Robinson PAT, et al. Controlled trial of cromoglycate and slow release aminophylline in perennial childhood asthma. BMf 1980;281:842.

29 Hiller EJ, Milner AD, Lenney W. Nebulized sodium cromoglycate in young asthmatic children. Arch Dis Child glycate in you
$1977 ; 52: 875-6$.

30 Matthew DJ. The use of nebulised sodium cromoglycate in children. Acta Allergol 1977;13(Suppl):34-43.

31 Hiller EJ, Milner AD. Betametasone 17 valerate aerosol and disodium cromoglycate in severe childhood asthma. $\mathrm{Br} \mathcal{F}$ Dis Chest 1975;69:103-7.

32 Crisp J, Ostrander C, Gianni A, et al. Cromolyn sodium therapy for chronic perennial asthma. $7 A M A$ 1974;229: $787-9$.

33 Hyde JS, Isenberg PD, Floro LD. Short- and longterm prophylaxis with cromolyn sodium in chronic asthma. Chest 1973;63:875-80.

34 Fox ZR, Brickman HF, Beaundry PH, et al. Response to disodium cromoglycate in children with chronic asthma. Can Med Assoc F 1972;106:975-9.

35 Silverman M, Connolly NM, Balfour L, et al. Long-term trial of disodium cromoglycate and isoprenaline in children with asthma. BMF 1972;3:378-81.

36 Collins-Williams C, Chiu AW, Lamenza C, et al. Treatment of bronchial asthma with disodium cromoglycate (Intal) in children. Ann Allergy 1971;29:613-20.

37 Limburg M. Treatment of children in an asthma centre with disodium cromoglycate. Acta Allergol 1971;26:367-82.

38 Hyde JS, Buranakul B, Vithayasai V. Effect of cromolyn sodium on childhood asthma. Ann Allergy 1970;28:44958.

39 Sly RM. Evaluation of disodium cromoglycate in asthmatic children. Ann Allergy 1970;28:299-306.

40 Shioda H, Murano J, Mishima K, et al. Disodium cromoglycate (Intal) in the treatment of bronchial asthma in children. Acta Allergol 1970;25:221-35.

41 Miraglia del Giudice M, Capristo A, Maiello N, et al. Nebulized sodium cromoglycate for the treatment of asthma in ulized sodium cromoglycate for the treatment of asthma in
children under five years of age. Mod Probl Paediat 1982;21: children

42 Smith JM, Devey GF. Clinical trial of disodium cromoglycate in treatment of asthma in children. BMF 1968;2: $340-4$

43 Yuksel B, Greenough A. Inhaled sodium cromoglycate for pre-term children with respiratory symptoms at follow-up. Respir Med 1992;86:131-4.

44 Bertelsen A, Andersen JB, Busch P, et al. Nebulised sodium cromoglycate in the treatment of wheezy bronchitis. Allergy 1986;41:266-70.

45 Geller-Bernstein C, Levin S. Sodium cromoglycate pressurised aerosol in childhood asthma. Curr Ther Res 1983;34: 345-9.

46 Marks MB. Therapeutic efficacy of cromolyn in childhood asthma. Am $\mathcal{F}$ Dis Child 1974;128:301-4.

47 Martinez FD, Wright AL, Taussig LM, et al. Asthma and wheezing in the first six years of life. $N$ Engl $f \mathrm{Med}$ 1995;332:133-8.

48 Silverman M. Outcome measures: an overview. Eur Respir $\mathcal{F}$ 1996;9(Suppl): $1-3$.

49 Edwards AM. Sodium cromoglycate (Intal) as an antiinflammatory agent for the treatment of chronic asthma. Clin Exp Allergy 1994;24:612-23.

50 Hoag JE, McFadden ER. Long-term effect of cromolyn sodium on nonspecific bronchial hyperresponsiveness: a review. Ann Allergy 1991;66:53-63.

51 Schweitzer M, Brossier Ballano K. Cromolyn use in young children. Ann Pharmacother 1994;28:886-7.

52 Holgate ST. Inhaled sodium cromoglycate. Respir Med 1996;90:387-90.

53 Cochrane Collaboration. Systematic Reviews. Cochrane Collaboration Software. Website www.cochrane.co.uk, visited January 2000 . 
54 Mulrow CD. Rationale for systematic reviews. BMf 1994;309:597-9.

55 Moher D, Jadad AR, Nichol G, et al. Assessing the quality of randomized controlled clinical trials: an annotated bibliography of scales and checklists. Control Clin Trials 1995;16 62-73.

56 Van Essen-Zandvliet EE, Hughes MD, Waalkens HJ, et al. Effects of 22 months treatment with inhaled corticosteroids and/or beta ${ }_{2}$-agonists on lung function, airway responsiveness and symptoms in children with asthma. Am Rev Respir Dis 1992;146:547-54.

57 Van Bever HP, Schuddinck L, Wojciechowski M, et al. Aerosolized budesonide in asthmatic infants. Pediatr Pulmonol 1990;9:177-80

58 Dickersin K, Chan S, Chalmers TC, et al. Publication bias and clinical trials. Control Clin Trials 1987;8:343-53. 